\title{
Self-harm on roads: register-based study of methods and characteristics of individuals involved
}

\author{
Keith Hawton ${ }^{\star a, b}$ Elizabeth Bale $^{\mathrm{a}}$ and Deborah Casey ${ }^{\mathrm{a}}$
}

aCentre for Suicide Research, Department of Psychiatry, University of Oxford, Warneford Hospital, OX29 6UP, UK

bOxford Health NHS Foundation Trust, Warneford Hospital, Oxford, OX29 6UP, UK

${ }^{*}$ Corresponding author

E-mail address: keith.hawton@psych.ox.ac.uk (K. Hawton) 


\section{ABSTRACT}

Background: Suicide on roads is receiving increased attention. However, there has been little research on non-fatal road-related self-harm. This study was conducted in order to investigate the characteristics of such acts.

Method: Information on non-fatal road self-harm was extracted from a self-harm monitoring system database of self-harm presentations to a major general hospital in England during 2005-2017. Patients were identified through being referred for psychosocial assessment by a clinical service and through scrutiny of medical records.

Results: During the 13-year study period 110 individuals (67 males, 43 females) presented to the hospital with road-related self-harm: 38 (34.5\%) jumped from bridges, $34(30.9 \%)$ jumped or lay in front of vehicles, 27 (24.5\%) crashed vehicles and $11(10.0 \%)$ jumped from moving vehicles. Crashing vehicles was more common in males and jumping from vehicles more common in females. In patients who received a psychosocial assessment, their most frequent problems were with a partner, employment and family members. Over half had been in psychiatric care and nearly two-thirds had a history of previous self-harm. Suicide intent was often high, especially in those who crashed a vehicle or jumped from a bridge.

Limitation: The study was based on presentations to a single hospital. Some data were not available for non-assessed patients.

Conclusions: Road-related self-harm, while not common, more frequently involves males and the acts are often of high suicidal intent. The range of problems preceding this method of self-harm indicates that there needs to be a variety of aftercare interventions, adapted to each individual's situation. 


\section{INTRODUCTION}

There is growing interest in prevention of suicide involving the road network, yet very limited research literature on the topic (Harrison, 2017). Suicides involving the road network are usually considered to include intentionally crashing a vehicle, jumping from a bridge or similar structure onto a road and jumping, stepping or lying in front of a moving vehicle (Harrison, 2017). Most attention has focussed on suicides involving crashing cars (Pompili et al., 2012). While not one of the foremost methods of suicide, the true extent of this method of suicide is not known. One reason is the difficulty of distinguishing between accidents and suicides involving motor vehicles, ascertainment of intent being a particular issue (Anderson and Svenson, 2015; Ohberg et al., 1997). The question of intent is also relevant to jumping from structures associated with roads and jumping or stepping in front of vehicles.

In a Scottish study it was estimated that $2.8 \%$ of all road traffic fatalities were suicides (Wyatt et al., 2009), a similar figure to that reported in a literature review (Pompili et al., 2012). However, the authors acknowledged that this may have been a considerable underestimate. Careful investigation of road traffic fatalities in Sweden resulted in a considerable increase in the number identified as suicides (Anderson and Svenson, 2015), similar to the finding of an earlier national study in Finland (Ohberg et al., 1997). From the limited available research literature it seems that the majority of those dying by suicide through crashing cars on the road network are relatively young males, often with a history of mental illness (especially depression), some having a prior history of self-harm/attempted suicide, and with alcohol misuse being a common feature (Ohberg et al., 1997; Routley et al., 2003) (Pompili et al., 2012; Wyatt et al., 2009). Much of what research has been done on 
the topic has focussed on single-driver suicide deaths (Pompili et al., 2012). However, as attention to suicide prevention has increased, there is growing interest in prevention of suicides on the road network more generally (Harrison, 2017).

One approach to investigating suicidal behaviour involving the road network is to study survivors of acts of intentional self-harm on roads. Having the opportunity to interview individuals can help provide insights into their characteristics that should have relevance to understanding and preventing suicidal behaviour on roads more generally. We have conducted a study of a consecutive series of individuals who presented to a major general hospital following non-fatal self-harm involving the road network. The aim was to describe their characteristics and clinical management, with a view to extending knowledge of this population and identifying factors relevant to clinical management and prevention.

\section{METHOD}

The study was based on data collected through the Oxford Monitoring System for Self-harm (Hawton et al., 2003). Through this system, information is recorded on all individuals presenting to the emergency department of the general hospital in Oxford following self-harm. Self-harm is defined as intentional non-fatal self-poisoning or self-injury, irrespective of type of motivation or degree of suicidal intent (Hawton et al., 2003). This is the same definition as used by the National Institute for Healthcare Excellence in its guide on self-harm (National Institute for Health and Clinical Excellence, 2011) and in publications in the field from other countries (e.g. Griffin et al, 2019; Witt and Robinson, 2019). It encompasses acts which might be viewed as suicide attempts and those where different motivation is involved. 
We used data for the 13-year period 2005-2017.

\subsection{Data collection}

For every patient who presents to the hospital having self-harmed and who receives a psychosocial assessment by a member of the hospital psychiatric service, a standardised data collection form is used to record a wide range of sociodemographic and clinical information for research purposes. In addition to sociodemographic details and method of self-harm, this also includes previous and current psychiatric treatment, previous self-harm, alcohol or drug misuse, nature of the patient's problems which contributed to the current episode of self-harm, and what aftercare arrangements are made. A member of the research team identifies patients who are not assessed by the psychiatric service through searches of the Emergency Department electronic records. For these cases information is collected regarding demographic characteristics and method of self-harm. Where patients have multiple presentations these are linked by use of unique person identifying numbers.

Definition of self-harm on the road network The following methods of self-harm were included:

i) Intentionally crashing a vehicle, such as into a road network structure (e.g. bridge support, tree, wall) or another vehicle (stationary or moving):

ii) Jumping from a bridge or similar structure;

iii) Jumping or lying in front of a moving vehicle; 
iv) Jumping from a moving vehicle. This category is additional to the methods usually involved in road-related suicidal behaviour (Harrison, 2017)

Suicide intent

As part of the psychosocial assessment the clinician conducting the assessment usually completes the Beck Suicide Intent Scale (SIS). The SIS is a 15-item questionnaire designed to assess the severity of suicidal intention associated with an episode of self-harm (Beck et al., 1974), which has been shown to have an association with suicide risk in the short term (Harriss et al., 2005). It has the advantage of providing scores on a continuum, which is in keeping with how many clinicians regard suicidal intent. Each item scores $0-2$, giving a total score range of $0-30$. The questionnaire is divided into two sections: the first eight items constitute the 'circumstances' section (part 1) and are concerned with the objective circumstances of the act of self-harm; the remaining seven items, in the 'self-report' section (part 2), are based on patients' own reconstruction of their feelings and thoughts at the time of the act. To examine the relationship between suicidal intent and patient characteristics, because the number of individuals involved was relatively small the total SIS scores were divided into two categories - 'low/moderate' (score 012) and 'high/very high' (13-30).

Comparison group of patients

For comparisons with other individuals who self-harmed during the study period we used all patients who had presented to the study hospital with other forms of selfinjury (excluding those where the act was combined with self-poisoning).

\subsection{Statistical analyses}


We present descriptive statistics for comparisons within the road self-harm sample and for those with individuals presenting with other forms of self-injury. All analyses were conducted using SPSS v25. We used a threshold for statistical significance of $p$ $<0.05$ throughout.

\subsection{Ethical approval}

The Oxford Monitoring System for Self-harm has approval from the NHS Health Research Authority (NRES Committee South Central - Berkshire) as well as from the Health Research Authority Confidentiality Advisory Group under Section 251 of the NHS Act 2006 (which allows collection of patient data without patient consent).

\section{RESULTS}

3.1 Road-related self-harm episodes During the 13-year study period 110 individuals presented to the study hospital following self-harm episodes on the road network. There were 115 episodes, the five repeat episodes involved three episodes of jumping from a bridge (two by one male and one by a female) and jumping in front of traffic (two by females). Because there were few repeat episodes involving roadrelated self-harm the results are presented by persons (i.e. each individual's first episode during the study period) rather than episodes.

The comparison group consisted of 2573 (1290 males; 1283 females) individuals who presented with other forms of self-harm, including self-cutting ( $N=1735)$, attempted hanging and suffocation ( $\mathrm{N}=258)$, and other methods $\mathrm{N}=580)$. 


\subsection{Demographic characteristics of individuals presenting with self-harm on}

roads

Nearly two-thirds of the individuals were males ( $\mathrm{N}=67 ; 60.9 \%$; see Table 1$)$. They were significantly older than the females $(z=1.48, p<0.05)$. Young people aged under 25 years were most frequently involved in road-related self-harm, mainly because over half the females (53.5\%) were in this age group (Table 1$)$. In terms of all individuals who presented to the hospital with self-injury during the study period, road-related self-harm represented $4.1 \%$ (110/2683) of person-based episodes), $4.9 \%$ of those involving males and $3.2 \%$ involving females.

\subsection{Methods used in self-harm on roads}

The most frequent road-related method of self-harm in males involved intentionally crashing a vehicle, but jumping from bridges and jumping/lying in front of vehicles were also frequent (see Table 1). In females, jumping from bridges onto roads was most frequent, followed by jumping/lying in front of moving vehicles and crashing a vehicle. Eight out of 11 episodes of jumping from a moving vehicle occurred in females.

(Table 1 about here)

\subsection{Admission to hospital and psychosocial assessment}

The vast majority of the individuals who presented to hospital with road-related selfharm were admitted to a hospital bed (97/110; $88.2 \%)$. This is a considerably greater proportion than for persons presenting with other self-injuries during the study period $\left(1735 / 2573 ; 64.4 \% ; x^{2}=20.97, p<0.001\right)$. Similarly, while in hospital most of the individuals with road-related self-harm received a psychosocial 
assessment from a mental health professional (92/110; 83.6\%), which was again more than in individuals presenting with other self-injuries $\left(1561 / 2573 ; 60.7 \% ; X^{2}=\right.$ 23.53. $p<0.001)$.

\subsection{Patient's Problems}

Information on the problems patients were facing at the time of self-harm was only available for patients who had a psychosocial assessment $(\mathrm{N}=91$ with this information). The most frequent problems in patients of both genders with roadrelated self-harm were those involving a partner, employment, and difficulties with family members (Table 2). Alcohol problems were identified in almost a third of the males. Psychiatric, housing and financial problems were also common.

(Table 2 about here)

\subsection{Psychiatric history}

Information on psychiatric history (assessed patients only) showed that at the time of their road-related self-harm, a quarter $(22 / 91 ; 24.2 \%)$ of the patients were in psychiatric care, which was similar to those presenting with other self-injuries $(412 / 1519 ; 27.1 \%)$. Over half $(47 / 83 ; 56.6 \%)$ had previously received psychiatric care (data missing for eight individuals), which was a similar proportion to those presenting with other self-injuries $\left(731 / 1405 ; 52.0 \% ; x^{2}=2.02, p=0.37\right)$.

Nearly two-thirds of those with road-related self-harm were known to have a history of previous self-harm (52/83; $62.7 \%$; data missing for eight patients), which was a 
smaller proportion than in those with other types of self-injury $\left(1313 / 1658 ; 79.2 \% ; X^{2}\right.$ $=14.5, p<0.001)$.

\subsection{Psychiatric aftercare}

There was little difference between the patients with road-related self-harm and those who presented with other types of self-injury in terms of the aftercare that was offered following their leaving hospital (assessed patients only), although somewhat more of those with road-related self-harm were admitted to psychiatric inpatient care $(14 / 92,15.2 \%$ v $168 / 1560,10.8 \%)$. Other outcomes were as follows; outpatient care (44/92, 47.8\% v 743/1560, 47.6\%); GP care (only) (29/92, 31.5\% v 521/1560, 33.4\%); other services (e.g. alcohol/drugs, complex needs, IAPT (Increasing Access to Psychological Services)) (4/92, 4.3\% v 125/1560, 8.0\%).

\subsection{Suicide intent}

Suicide intent associated with self-harm based on scores on the Beck Suicide Intent Scale (assessed patients only; $\mathrm{N}=70$ ) was greater in those with road-related selfharm than in those presenting with other self-injuries $(z=5.87, p<0.001)$. This applied to both genders (males; $z=4.29, p<0.001$; females: $z=3.39, p=0.001$ ). Overall, nearly half of those with road-related self-harm $(\mathrm{N}=34 ; 48.6 \%)$ scored in the high/very high range (13 and over). As shown in Table 3, there were differences between the methods of road self-harm in the proportions who scored in the high/very high range compared with those in the low/very low range $(0-12)\left(x^{2}=11.97, d f 3, p=0.007\right)$. High/very high scores were recorded for more than two-thirds of those who intentionally crashed a vehicle (68.0\%) and over half of those who jumped from a bridge (55.0\%), and approximately a third (31.6\%) of those who jumped in front of a vehicle, while all six individuals who jumped from a vehicle scored in the low range. 
(Table 3 about here)

\section{DISCUSSION}

While prevention of suicides on the road network is attracting increased attention (Harrison, 2017), there is little evidence on which to base prevention initiatives. One approach to gathering evidence is through careful and thorough investigation of individual deaths likely to be road-related suicides (Anderson and Svenson, 2015; Ohberg et al., 1997). Another is, as we have done, through investigation of non-fatal suicidal acts on the road network, the assumption being that a substantial proportion of them could have ended up being fatal were it not for chance, poor execution of the act or intervention by others. The relatively high proportions of individuals in this study for whom the Suicide Intent Scale scores indicated high intent support this contention, except for acts involving jumping from a moving vehicle, where of the small number of individuals involved who had a psychosocial assessment there were none with a high intent score. This may explain why this method is not usually included in classification of road-related suicides (Harrison, 2017). High intent scores were particularly associated with intentionally crashing a vehicle and jumping from a bridge.

Two-thirds of the self-harm episodes involved males, which is very different to the gender ratio for self-harm in general, in which more females than males are involved (Geulayov et al., 2016). However, the male preponderance, except for acts involving jumping from a moving vehicle, is in keeping with data on road-related suicides 
(Ohberg et al., 1997; Pompili et al., 2012; Routley et al., 2003; Wyatt et al., 2009), as well as suicides in general (World Health Organisation, 2014).

Just over $40 \%$ of those who presented with road-related self-harm were aged under 25 years, with $53.5 \%$ of females in this age group. Road-related self-harm constituted a relatively small proportion of all presentations involving self-injury (4.1\%). Similarly, road-related suicides represent a relatively small proportion of overall suicides, although the numbers of road-related suicides are likely to be underestimated (Anderson and Svenson, 2015; Ohberg et al., 1997)

As might be expected, the vast majority of individuals were admitted to a bed in the general hospital. Also, most received a psychosocial assessment from a mental health practitioner. This is in accord with UK National Guidance on Clinical Management of Self-harm (National Institute for Health and Clinical Excellence, 2011), although for other methods of self-harm the rate of psychosocial assessment is often far lower (Cooper et al., 2013; Geulayov et al., 2016). In such an assessment it is crucial to cover a range of factors (e.g. problems that resulted in the act of self-harm, psychiatric disorder, previous psychiatric history, suicidal intent and other motives for the act, personal resources - both psychological and practical risks and attitudes to aftercare), and to plan with the patient the most appropriate aftercare (National Institute for Health and Clinical Excellence, 2011) and also to conduct safety planning with them (Stanley and Brown, 2012).

Problems commonly facing the individuals of both genders who self-harmed on the road network in the present study were those involving a partner, employment difficulties and problems with family members. Psychiatric problems were identified in approximately a quarter of individuals. Problems related to alcohol use were 
identified in approximately a third of the males and a quarter of the females.

Financial problems were present in a quarter of the males. Such difficulties should be the focus of aftercare interventions, depending on the specific difficulties facing the individual patient.

While the prevalence of previous and current psychiatric care at the time of roadrelated self-harm was not different from that for most other individuals presenting to hospital following self-injury, the fact that almost a quarter (24.2\%) were in psychiatric care at the time of self-harm and over half (56.6\%) had received psychiatric care previously, together with the prevalence of psychiatric problems noted above, indicates that psychiatric disorders were a prominent feature in many individuals. This is again in keeping with what is known from other studies of individuals involved in road-related suicide (Ohberg et al, 1997; Routley et al, 2003; Pompili et al, 2012). Nearly two-thirds (62.7\%) of the individuals involved in roadrelated self-harm had engaged in previous episodes of self-harm.

One question is how self-harm and suicides on the road network might compare with these acts on railways, including underground trains. The latter have received far more attention in terms of both research and prevention (Mishara and Bardon, 2016; Barker et al, 2017). Those dying by suicide on the rail network appear to be similar to those dying on the road network, such as often being relatively young compared with people dying by suicide in general, and often with problems with substance misuse and a history of previous suicide attempts involving other methods (Mishara and Bardon, 2016). However, there is little information regarding non-fatal acts in on the rail network, probably because of their generally high case fatality, but some on survivors of suicide attempts on the underground, who report that their acts were often impulsive but involved high suicide intent (O'Donnell et al, 1996). It is uncertain 
how individuals who self-harm by jumping on the road network differ from those who jump in other locations (Cantor et al, 1989; Gunnell and Nowers, 1997). However, jumping on the road network is particularly likely to threaten the safety of other people, especially drivers, and is a focus of current prevention policy, having received little specific attention in the past (Harrison, 2017; Okolie et al, 2020).

Another question is what differences are there between individuals involved in fatal and non-fatal acts of self-harm on roads. There is likely to be little difference between individuals involved in fatal and non-fatal acts involving crashing cars, with chance or poor execution of the act probably being major factors in non-fatal episodes. The same is likely to apply to jumping onto roads. However, there may well be differences between individuals involved in fatal and non-fatal acts involving jumping or lying in front of vehicles. Our findings, although based on a small number of cases, suggest that jumping from a car will rarely be a method of suicide.

In terms of classification of road-related self-harm we believe that jumping from a moving vehicle should be added to the customary classification. While such acts may less often be fatal than other methods on the road network, they are not so different behaviourally from acts such as jumping from trains, which are included in rail suicide and attempted suicide statistics. However, the findings of our study would suggest that they usually involve low suicide intent, raising the possibility that they represent impulsive behaviour, perhaps related to altercations with others in the vehicle.

\subsection{Strengths and Limitations}

This study is based on carefully collected information on individuals involved in roadrelated self-harm acts identified over a lengthy period of time. However, the study 
was of presentations to a single major general hospital. We cannot assume therefore that the findings are representative of road-related self-harm nationally. We would encourage other centres to collect such information to provide a more representative picture.

Data were missing for some individuals, mainly because they did not receive a psychosocial assessment. This was more likely where individuals left the hospital without being admitted, in which case a psychosocial assessment would have been less likely (Kapur et al., 2008). Thus we may have more detailed information on the more physically severe cases, which could be a potential source of bias in our findings.

\subsection{Conclusions}

Like suicide on roads, self-harm on the road network is relatively uncommon, but clearly important in view of the high likelihood of death. Also, this method of suicidal behaviour may present hazards for other individuals. We have shown some gender differences in the specific methods of road-related self-harm, with intentionally crashing a vehicle being the most common in males and jumping from a bridge or in front of a vehicle the most frequent methods in females. The nature of the problems preceding self-harm on the road network was diverse, suggesting that prevention and aftercare need to be multi-modal and adapted to the individual's situation. There also needs to careful assessment of the extent to which suicidal ideation precedes such acts as this might also help gauge future risk of suicide (Pompili et al, 2016; Hubers et al, 2018). This should include inquiry about development and duration of thoughts about the act. However, the difficulties involved in predicting suicide risk (Large et al., 2016) must be acknowledged. 
We suggest that jumping from a moving vehicle should be added to the usual classification of road-related suicidal behaviour. Finally, we encourage further research into this phenomenon, preferably involving in-depth interviews with patients to identify the nature of their difficulties and their reasons for choosing this method of suicidal behaviour. 


\section{Funding}

The Oxford Monitoring System is supported by funding from the Department of Health and Social Care as part of the Multicentre Study of Self-harm in England. Professor Hawton is supported by Oxford Health NHS Foundation Trust. He is a National Institute for Health Research Emeritus Senior Investigator. Neither the Department of Health and Social Care nor NIHR had any role in the design of the work or interpretation of the findings. The views expressed are those of the authors and not necessarily those of the Department of Health and Social Care nor the National Institute for Health Research.

\section{Acknowledgements}

We thank members of the Emergency Department Psychiatric Service in the Barnes Unit at the John Radcliffe Hospital who collected the data on patients receiving psychosocial assessments. 


\section{REFERENCES}

Anderson, A.-L., Svenson, K., 2015. Fatalities in road traffic, a result of accidents or suicides. Journal of Local and Global Health Science 27.

Barker, E., Kolves, K., De Leo, D., 2017. Rail - suicide prevention: Systematic literature review of evidence - based activities. Asia - Pacific Psychiatry, 9:e12246.

Beck, A., Schuyler, D., Herman, J., 1974. Development of suicidal intent scales, In: Beck, A., Resnik, H., Lettieri, D.J. (Eds.), The Prediction of Suicide. Charles Press, Maryland, pp. 45-56.

Cantor, C.H., Hill, M.A., McLachlan, E.K., 1989. Suicide and related behaviour from river bridges: a clinical perspective. British Journal of Psychiatry, 155, 829-835.

Cooper, J., Steeg, S., Bennewith, O., Lowe, M., Gunnell, D., House, A., Hawton, K., Kapur, N., 2013. Are hospital services for self-harm getting better? An observational study examining management, service provision and temporal trends. . personal communication.

Geulayov, G., Kapur, N., Turnbull, P., Clements, C., Waters, K., Ness, J., Townsend, E., Hawton, K., 2016. Epidemiology and trends in non-fatal self-harm in three centres in England, 2000-2012: findings from the Multicentre Study of Self-harm in England. BMJ Open 6, e010538.

Griffin, E., McTernan N., Wrigley, C., Nicholson, S., Arensman, E., Williamson, E., Corcoran, P., 2019. National Self-Harm Registry Ireland Annual Report 2018. Cork: National Suicide Research Foundation.

Gunnell, D., Nowers, M., 1997. Suicide by jumping. Acta Psychiatrica Scandinavica, 96, 1-6.

Harrison, K., 2017. Suicides on UK Roads: Lifting the Lid. Parliamentary Advisory Council for Transport Safety, London.

Harriss, L., Hawton, K., Zahl, D., 2005. Value of measuring suicidal intent in the assessment of people attending hospital following self-poisoning or self-injury. British Journal of Psychiatry 186, 60-66.

Hawton, K., Harriss, L., Hall, S., Simkin, S., Bale, E., Bond, A., 2003. Deliberate selfharm in Oxford, 1990-2000: a time of change in patient characteristics. Psychological Medicine 33, 987-996.

Hubers, A.A.M., S. Moaddine, S., Peersmann, S.H.M., Stijnen, T., van Duijn, E., van der Mast, R.C., Dekkers O.M., Giltay, E.J., 2018. Suicidal ideation and subsequent completed suicide in both psychiatric and non-psychiatric populations: a meta-analysis. Epidemiology and Psychiatric Sciences 27, 186-198.

Kapur, N., Murphy, E., Cooper, J., Bergen, H., Hawton, K., Simkin, S., Casey, D., Horrocks, J., Lilley, R., Noble, R., Owens, D., 2008. Psychosocial assessment following self-harm: results from the Multi-Centre Monitoring of Self-Harm Project. Journal of Affective Disorders 106, 285-293. 
Large, M., Kaneson, M., Myles, N., Myles, H., Gunaratne P., Ryan, C., 2016. Metaanalysis of longitudinal cohort studies of suicide risk: assessment among psychiatric patients: heterogeneity in results and lack of improvement over time. PLoS ONE 11(6): e0156322.

Mishara, B. L., Bardon, C., 2016. Systematic review of research on railway and urban transit system suicides. Journal of Affective Disorders193, 215-226.

National Institute for Health and Clinical Excellence, 2011. Self-harm: longer-term management CG133. National Institute for Health and Clinical Excellence, Manchester.

O'Donnell, I., Farmer, R., Catalán, J., 1996. Explaining suicide: The views of survivors of serious suicide sttempts. British Journal of Psychiatry, 168, 780-786.

Ohberg, A., Penttila, A., Lonnqvist, J., 1997. Driver suicides. British Journal of Psychiatry 171, 468-472.

Okolie, C., Hawton, K., Lloyd, K., Price, S.F., Dennis, M., John,A., 2020. Means restriction for the prevention of suicide on roads. Cochrane Database of Systematic Reviews, Issue 9. Art. No.: CD013738.

Pompili M., Belvederi Murri, M., Patti, S., Innamorati, M., Lester, D., Girardi, P., Amore, M., 2016.The communication of suicidal intentions: a meta-analysis. Psychological Medicine 46, 2239-2253.

Pompili, M., Serafini, G., Innamorati, M., Montebovi, F., 2012. Car accidents as a method of suicide: a comprehensive overview. Forensic Science International 223, 1-3.

Routley, V., Staines, C., Brennan, C., Haworth, N., Ozanne-Smith, K., 2003. Suicide and natural deaths in road traffic: review. Monash University Accident Research Centre, Australia.

Stanley, B., Brown, G.K., 2012. Safety planning intervention: A brief intervention to mitigate suicide risk. . Cognitive and Behavioral Practice 19, 256-264.

Witt, J., Robinson, J., 2019 Sentinel surveillance for self-harm: existing challenges and opportunities for the future. Crisis 40, 1-6.

World Health Organisation, 2014. Preventing Suicide: A Global Imperative. World Health Organisation, Geneva.

Wyatt, J.P., Squires, T., Collis, S., Broadley, R., 2009. Road traffic suicides Journal of Forensic Legal Medicine 16, 212-214. 
Table 1

Non-fatal self-harm on the road network: patients presenting to the general hospital 2005-2017 (13 year period)

\begin{tabular}{|c|c|c|c|c|c|c|}
\hline \multirow[b]{2}{*}{ Gender } & \multicolumn{2}{|c|}{$\underset{\mathbf{N}}{\text { Males }}$} & \multicolumn{2}{|c|}{$\begin{array}{c}\text { Females } \\
\mathbf{N}\end{array}$} & \multicolumn{2}{|c|}{$\begin{array}{c}\text { Both genders } \\
\qquad \mathbf{N}\end{array}$} \\
\hline & 67 & $60.9 \%$ & 43 & $39.1 \%$ & 110 & $100 \%$ \\
\hline \multicolumn{7}{|l|}{ AGE (years) } \\
\hline Mean (SD) & 34.2 & $(14.1)$ & 28.8 & (13.3) & 32.1 & $(14.0)$ \\
\hline Range & $15-65$ & & $12-64$ & & $12-65 \mathrm{yrs}$ & \\
\hline Age group & $\mathbf{N}$ & $\%$ & $\mathbf{N}$ & $\%$ & $\mathbf{N}$ & $\%$ \\
\hline $\begin{array}{l}<=24 \text { yrs } \\
25-34 \text { yrs } \\
35-54 \text { yrs } \\
55-65 \text { yrs }\end{array}$ & $\begin{array}{r}24 \\
13 \\
22 \\
8\end{array}$ & $\begin{array}{l}35.8 \% \\
19.4 \% \\
32.8 \% \\
11.9 \%\end{array}$ & $\begin{array}{r}23 \\
9 \\
9 \\
2\end{array}$ & $\begin{array}{r}53.5 \% \\
20.9 \% \\
20.9 \% \\
4.7 \%\end{array}$ & $\begin{array}{l}47 \\
22 \\
31 \\
10\end{array}$ & $\begin{array}{c}42.7 \% \\
20.0 \% \\
28.2 \% \\
9.1 \%\end{array}$ \\
\hline $\begin{array}{l}\text { Road-related self-harm as } \\
\text { proportion of all patients who } \\
\text { self-injured }\end{array}$ & $67 / 1357$ & $4.9 \%$ & $43 / 1326$ & $3.2 \%$ & $110 / 2683$ & $4.1 \%$ \\
\hline $\begin{array}{l}\text { Methods used } \\
\text { Crashed a vehicle } \\
\text { Jump from bridge } \\
\text { Jumping/lying in front of } \\
\text { moving vehicle }\end{array}$ & $\begin{array}{r}\mathbf{N} \\
23 \\
20 \\
21\end{array}$ & $\begin{array}{l}\% \\
34.3 \% \\
29.9 \% \\
31.3 \%\end{array}$ & $\begin{array}{r}\mathbf{N} \\
4 \\
18 \\
13\end{array}$ & $\begin{array}{l}\text { \% } \\
9.3 \% \\
41.9 \% \\
30.2 \%\end{array}$ & $\begin{array}{r}\mathbf{N} \\
27 \\
38 \\
34\end{array}$ & $\begin{array}{l}\% \\
24.5 \% \\
34.5 \% \\
30.9 \%\end{array}$ \\
\hline $\begin{array}{l}\text { Jumping from a moving } \\
\text { vehicle }\end{array}$ & 3 & $4.5 \%$ & 8 & $18.6 \%$ & 11 & $10.0 \%$ \\
\hline
\end{tabular}


Table 2

Main problems faced by patients involved in road-related self-harm ${ }^{1}$

\begin{tabular}{|c|c|c|c|c|c|c|c|c|}
\hline \multirow[t]{2}{*}{ Problems } & \multicolumn{2}{|l|}{ Overall } & \multicolumn{2}{|l|}{ Males } & \multicolumn{4}{|l|}{ Females } \\
\hline & $\mathrm{N}=91$ & $(\%)$ & $\mathrm{N}=57$ & (\%) & $\mathrm{N}=34$ & $(\%)$ & $\mathrm{X}^{2}$ & $\mathbf{P}$ \\
\hline Partner & 40 & $(44.0)$ & 26 & $(45.6)$ & 14 & $(41.2)$ & 0.17 & 0.83 \\
\hline Employment & 34 & (37.4) & 21 & (36.8) & 13 & (38.2) & 0.02 & 1.00 \\
\hline Family & 32 & $(35.2)$ & 19 & (33.3) & 13 & (38.2) & 0.22 & 0.66 \\
\hline Alcohol & 24 & (26.4) & 18 & (31.6) & 6 & (17.6) & 2.13 & 0.22 \\
\hline Psychiatric problem & 24 & (26.4) & 13 & (22.8) & 11 & (32.4) & 1.00 & 0.34 \\
\hline Housing & 21 & (23.1) & 12 & (21.1) & 9 & (26.5) & 0.35 & 0.61 \\
\hline Financial & 18 & (19.8) & 14 & (24.6) & 4 & (11.8) & 2.20 & 0.18 \\
\hline Drugs & 13 & $(14.3)$ & 9 & (15.8) & 4 & (11.8) & 0.88 & 0.60 \\
\hline Social isolation & 11 & $(12.1)$ & 8 & (14.0) & 3 & ( 8.8) & 0.54 & 0.53 \\
\hline Friends & 9 & $(9.9)$ & 4 & $(7.0)$ & 5 & (14.7) & 1.41 & 0.29 \\
\hline
\end{tabular}

${ }^{1}$ More than one problem could be recorded for each patient 
Table 3

Suicide intent scores in those self-harming on road network, by specific method of self-harm

\begin{tabular}{|c|c|c|c|c|c|c|}
\hline \multirow[t]{2}{*}{ Suicide Intent Scale Score } & $\begin{array}{l}\text { Jump in } \\
\text { front of } \\
\text { vehicle }\end{array}$ & $\begin{array}{l}\text { Jump from } \\
\text { moving } \\
\text { vehicle }\end{array}$ & $\begin{array}{l}\text { Jump from } \\
\text { bridge }\end{array}$ & $\begin{array}{l}\text { Crashed } \\
\text { vehicle }\end{array}$ & \multicolumn{2}{|c|}{ Total } \\
\hline & N $(\%)$ & N $(\%)$ & $(\%)$ & $(\%)$ & $\mathbf{N}$ & $(\%)$ \\
\hline High/very high SIS (score 13-13) & $6 \quad(31.6)$ & $0 \quad(0.0)$ & $11(55.0)$ & $17(68.0)$ & 34 & $(48.6)$ \\
\hline Low/very low SIS (score 0-12) & $13(68.4)$ & $6(100.0)$ & $9(45.0)$ & $8 \quad(32.0)$ & 36 & $(51.4)$ \\
\hline Total & $19(100.0)$ & $6(100.0)$ & $20(100.0)$ & $25(100.0)$ & 70( & 100.0) \\
\hline
\end{tabular}

